\title{
The use of CONOX as a guide to the general anesthesia on laparotomy patients compared with standard clinical care- A pilot study
}

\author{
Brillyan T Jehosua' \\ I Putu Pramana Suarjaya ${ }^{2}$ \\ IGAG Utara Hartawan ${ }^{2}$ \\ Tjokorda Gde Agung Senapathi ${ }^{3}$
}

\begin{abstract}
'Resident at Department of Anesthesiology, Pain Management, and Intensive Care, Udayana University, Sanglah General Hospital,

Denpasar-Bali, Indonesia.

${ }^{2}$ Lecturer at Department of Anesthesiology,

Pain Management, and Intensive Care, Udayana

University, Sanglah General Hospital,

Denpasar-Bali, Indonesia.

${ }^{3}$ Associate Professor at Department of

Anesthesiology, Pain Management, and

Intensive Care, Udayana University, Sanglah

General Hospital, Denpasar-Bali, Indonesia.
\end{abstract}

\section{Cite this article:}

Jehosua BT, Suarjaya IPP, Hartawan IGAGU, Senapathi TGA. The use of CONOX as a guide to the general anesthesia on laparotomy patients compared with standard clinical care - A pilot study. Neurologico Spinale Medico Chirurgico. 202I.4(2)5I-54. DOI: I0.36444/nsmc.v4i2.I 58

\section{Corresponding author:}

\section{Brillyan $T$ Jehosua}

Resident at Department of Anesthesiology, Pain Management, and Intensive Care, Udayana University, Sanglah General Hospital, DenpasarBali, Indonesia brlbius2017@gmail.com

\begin{abstract}
Background: Avoiding excessive doses of anesthesia was fundamental, mainly to reduce the adverse effect of anesthesia. Electroencephalography (EEG)-based monitors can be used to measure the depth level of anesthesia and guide intraoperative hypnosis drug and opioid administration. This study aims to evaluate the benefit of using CONOX monitor when administering anesthesia drugs in laparotomy procedures.
\end{abstract}

Method: Twenty patients aged 18-65 years with physical status ASA I-III who underwent major laparotomy surgery with general anesthesia total intravenous anesthesia (TIVA) were divided into two groups. Group A received general anesthesia guided with the CONOX monitor, while group B using standard clinical care. We later evaluate the total use of propofol and fentanyl, intraoperative hemodynamic profile, postoperative cognitive disorder (POCD), intraoperative awareness, postoperative nausea and vomiting (PONV), and moderate to severe pain in the postanesthesia care unit (PACU).

Results: The mean total propofol used is lower in CONOX group $(63.6 \pm 11.7 \mathrm{mcg} / \mathrm{kg} / \mathrm{min}$ vs. 74 $\pm 17.87 \mathrm{mcg} / \mathrm{kg} / \mathrm{min}$ ). A similar result was obtained with fentanyl. The CONOX group use a lower total of fentanyl $(212.5 \pm 32.3 \mathrm{mcg}$ vs. $249 \pm 54.6 \mathrm{mcg})$ than the control group. POCD was found to be more prevalent in the control group ( $5 \mathrm{vs} 2$ patients). While there is no report of intraoperative awareness.

Conclusion: The incidence of PONV and moderate to severe pain in PACU was similar between the two groups. This pilot study is a preliminary study to evaluate the benefit of using EEG-based monitors to adjust anesthesia drugs.

Keywords: Video laryngoscope, C-MAC, McGrath®, Intubation, Cormack Lehane degree, POGO score

\section{Introduction}

Given the intensity of the pain, stimulation may vary throughout the surgery. Since the hemodynamic effect of anesthesia drugs is dose-dependent, which may limit the dose that we can 
administer to the patient, frequently, there is an imbalance between anesthesia needs and the drugs that can be safely administered. Instead, wrong drug titrations can also lead to excessive depth of anesthesia and can interfere with patient outcome.

Avoiding excessive doses of anesthesia was very important, not only because there is the possibility to reduce the adverse effect of anesthesia, such as hemodynamic instability, but also to prevent the delay of patient recovery from anesthesia. ${ }^{2}$

Monitoring the effects of anesthetic drugs by measuring the depth of anesthesia can help optimize the quality of the drug administration, reduce costs, and improve patients outcomes. ${ }^{1}$ Monitoring the depth of anesthesia using the digital EEG processing help to minimize anesthesia and opioid dose perioperative, which can also help reduce the POCD and another undesirable effect. ${ }^{3,4}$

The CONOX monitor is one of the anesthesia depth monitoring tools that capture the EEG signal from the brain, which has two parameters, namely qCON and qNOX. qCON is an index of the level of anesthesia depth, while qNOX is a predictive level of response to pain stimuli. qCON and qNOX index is based on a combination of different band frequencies, which is inserted into the Adaptive NeuroFuzzy Inference System (ANFIS), which produces output on a scale of $0-99.5$

This is a pilot study to evaluate the benefit of using CONOX monitor to guide the anesthesiologist when administering anesthesia drugs (propofol and fentanyl) in laparotomy procedures, compared with patients using standard clinical care.

\section{Methods}

This preliminary experimental prospective study was done in a teaching hospital from December 2020 to March 2021. After ethics approval and written informed consent were obtained, blind randomization 20 patients aged 18-65 years with physical status ASA I-III who underwent major laparotomy surgery with general anesthesia TIVA were selected as samples. These were divided into two groups. Group A consists of ten subjects who received general anesthesia guided with CONOX monitor, while group B with ten subjects using standard clinical care with standard monitor (non-invasive blood pressure, heart rate, respiratory rate, peripheral oxygen saturation). During surgery, the qCON value was maintained at $40-60$. When it decreases $<40$, the continuous propofol dose was reduced. When the value increases to $>60$, the continuous propofol dose was increased. During the surgery, the qNOX value was maintained at 40-60. If it below 60 , the patient was given an additional one $\mathrm{mcg} / \mathrm{kg}$ of fentanyl. Later we sum the total use of propofol and fentanyl, intraoperative hemodynamic profile (blood pressure, heart rate), POCD incident, the incidence of intraoperative awareness, PONV, and moderate to severe pain in the PACU. Hyperalgesia, a decrease in consciousness, psychiatry problem, low cognitive function, ventilator using postsurgery were exclusion criteria of the study. Independent $\mathrm{T}$-Test was used to analyze the result.

\section{Results}

We collected data from 20 samples. No samples were excluded. Patient characteristics were shown in table 1. From intraoperative use of propofol, the highest use of propofol in the CONOX group was $90 \mathrm{mcg} / \mathrm{kg} / \mathrm{min}$, and the lowest was $40 \mathrm{mcg} / \mathrm{kg} / \mathrm{min}$. While in the control group, the highest concentration was 106 $\mathrm{mcg} / \mathrm{kg} / \mathrm{min}$, while the lowest was $61 \mathrm{mcg} / \mathrm{kg} / \mathrm{min}$. The result shows no statistical significance difference in both groups.

Table 1. Patient characteristic of the study

\begin{tabular}{|c|c|c|c|}
\hline \multirow{3}{*}{ Age (years) } & $18-40$ & \multirow[t]{3}{*}{$\mathrm{n}=$} & 5 \\
\hline & $41-50$ & & 9 \\
\hline & $>50$ & & 6 \\
\hline \multirow{2}{*}{ Sex } & Male & \multirow[t]{2}{*}{$\mathrm{n}=$} & 8 \\
\hline & Female & & 12 \\
\hline \multirow{2}{*}{$\begin{array}{l}\text { ASA Physical } \\
\text { Status }\end{array}$} & I-II & \multirow[t]{2}{*}{$\mathrm{n}=$} & 11 \\
\hline & III & & 9 \\
\hline \multirow{2}{*}{ Body Weight (kg) } & $30-50$ & \multirow[t]{2}{*}{$\mathrm{n}=$} & 3 \\
\hline & $>50$ & & 17 \\
\hline \multirow{2}{*}{ Operation Duration } & $1-2$ hours & \multirow[t]{2}{*}{$\mathrm{n}=$} & 9 \\
\hline & 3 hours & & 11 \\
\hline
\end{tabular}

For the fentanyl concentration, the highest use of total fentanyl in the CONOX group was $250 \mathrm{mcg}$, and the lowest was 150 mcg. While in the control group, the highest concentration was 300 $\mathrm{mcg}$, while the lowest was $150 \mathrm{mcg}$. The result shows the use of fentanyl was statistically less in the CONOX group ( $\mathrm{p}<0.05)$.

Both results show a higher concentration of propofol and fentanyl use in the control group, as shown in table 2 .

The number of hemodynamic disturbance incidents for the CONOX group was less than in the control group $(2.5 \pm 0.98$ vs. $4.8 \pm$ 1.2 times). On the other hand, the POCD incident was higher in the control group ( 2 patients vs 5 patients). At the same time, there is no report of intraoperative awareness. The incidence of PONV and 
moderate to severe pain in PACU was similar between the two groups (table 3).

Table 2. Comparison of mean propofol and total fentanyl consumption between two groups

\begin{tabular}{|c|l|l|l|l|}
\hline \multirow{2}{*}{$\begin{array}{c}\text { Total Propofol per } \\
\mathrm{kg} / \mathrm{mnt}( \pm \mathrm{SD})\end{array}$} & $\begin{array}{l}\text { CONOX } \\
(\mathrm{n}=10)\end{array}$ & $\begin{array}{l}63.6( \pm 11.7) \\
\mathrm{mcg} / \mathrm{kg} / \mathrm{min}\end{array}$ & $\begin{array}{l}\mathrm{P} \\
\text { Value }\end{array}$ & .11 \\
\cline { 2 - 4 } & $\begin{array}{l}\text { Control } \\
(\mathrm{n}=10)\end{array}$ & $\begin{array}{l}74( \pm 17.87) \\
\mathrm{mcg} / \mathrm{kg} / \mathrm{min}\end{array}$ & & \\
\hline \multirow{2}{*}{$\begin{array}{c}\text { Total Fentanyl } \\
\text { intraoperative }( \pm \\
\text { SD })\end{array}$} & $\begin{array}{l}\text { CONOX } \\
(\mathrm{n}=10)\end{array}$ & $\begin{array}{l}212.5 \\
( \pm 32.3) \mathrm{mcg}\end{array}$ & Value & \\
\cline { 2 - 3 } & $\begin{array}{l}\text { Control } \\
(\mathrm{n}=10)\end{array}$ & $\begin{array}{l}249( \pm 54.6) \\
\mathrm{mcg}\end{array}$ & & \\
\hline
\end{tabular}

Table 3. Perioperative complication

\begin{tabular}{|l|l|l|}
\hline & CONOX & Control \\
\hline $\begin{array}{l}\text { Intraoperative Hemodynamic } \\
\text { Instability (times)* }( \pm \text { SD) }\end{array}$ & $2.5 \pm 0.98$ & $4.8 \pm 1.2$ \\
\hline POCD $^{+}$ & 2 & 5 \\
\hline Intraoperative Awareness ${ }^{\dagger}$ & 0 & 0 \\
\hline $\begin{array}{l}\text { PONV (Post Operative Nausea } \\
\text { and Vomiting) in PACU }\end{array}$ & 1 & 1 \\
\hline $\begin{array}{l}\text { Pain score (NRS/ Numerical } \\
\text { Rating Scale) }>3 \text { in PACU }\end{array}$ & 3 & 2 \\
\hline
\end{tabular}

* Hemodynamic instability is defined as how many times there are changes in hemodynamic parameter (Blood pressure / BP and Heart rate / $\mathrm{HR} \pm 20 \%$ from baseline)

+ POCD (Post Operative Cognitive Disorder) was assessed using MMSE score

+ Intraoperative Awareness was assessed using Modified Brice Questionnaire (MBQ)

\section{Discussion}

The depth of anesthesia can be assessed by indices derived from the EEG. The electroencephalography-based monitor will allow objective and sustained measurement of the depth of anesthesia even when the patient is already in a state of total paralysis or has lost all response to painful external stimuli.

CONOX has two parameters, qCON and $\mathrm{qNOX}$. Both indexes are working with the captured EEG signal of the brain. qCON is an index of the depth level of anesthesia while qNOX is a predictive level of pain stimuli response. ${ }^{5}$

The qCON processes the EEG information from frontal lobe and reflects the level of anesthesia that is estimated as the number between 99 (completely awake) and 0 (isoelectric EEG). Index qCON $\geq 80$ is associated with a conscious state or mild sedation, and the range of the index from 60 to 40 relates to the adequate level of anesthesia for surgery (table 4$){ }^{6}$

Table 4. $q C O N$ and $q N O X$ score interpretation

\begin{tabular}{|c|c|c|}
\hline Score & qCON & qNOX \\
\hline $80-99$ & Full Awareness & \multirow{2}{*}{$\begin{array}{l}\text { Patient is fully responsive to pain } \\
\text { stimulus }\end{array}$} \\
\hline 75 & Sedation & \\
\hline $40-60$ & $\begin{array}{l}\text { General } \\
\text { Anesthesia }\end{array}$ & $\begin{array}{l}\text { Patient is less responsive to pain } \\
\text { stimulus }\end{array}$ \\
\hline 20 & Deep Anesthesia & \multirow{2}{*}{$\begin{array}{l}\text { Patient is more likely to show no } \\
\text { response to pain stimulus }\end{array}$} \\
\hline 0 & Isoelectric EEG & \\
\hline
\end{tabular}

Both the qCON and qNOX indices can detect movement in response to noxious stimuli, although the response is greater on qNOX than on qCON. It can occur because an increase in qNOX is the effect of EEG directly from dangerous stimulation, while qCON increased due to the secondary effect of dangerous stimulation. Both qCON and qNOX can be affected by the use of muscle relaxants, as has been published using other EEG monitors. ${ }^{5}$

Several studies have shown that nociception monitors can be used to predict postoperative pain, guide intraoperative opioid administration, and predict the need for analgesia during the initial postoperative period. From the results obtained in this study, in the CONOX group, the mean average use of propofol doses based on body weight was smaller than that of the control group. However, the result was not statically different. The proper use of propofol as needed will also reduce the side effects of propofol.

The hypotensive effect of propofol is dose-dependent, which will also affect the patient's hemodynamics. Hemodynamics in the CONOX group were found to be more stable as shown in table 3 . The incidence of blood pressure and pulse exceeding or decreasing $20 \%$ of the baseline was half less frequent than in the control group. The hypotension usually happens during the induction, and the increase in blood pressure or heart rate usually occurs during intubation or extubation. In general practice, pulse and blood pressure are some of the parameters that alert the anesthesiologist that the patient feels a pain response or the depth of anesthesia is not adequate. ${ }^{7}$ This can be helped by using CONOX so that the propofol level can be easily adjusted 
according to the desired depth of anesthesia. ${ }^{8}$

Similar results were obtained for fentanyl. CONOX's ability to predict patient awareness due to pain stimulation can assist anesthesiologists in increasing doses of sedation, analgesics, and muscle relaxants. ${ }^{4}$

Some of the observed adverse events, such as POCD, were found to be more prevalent in the control group (5 vs 2 patients), which is closely related to the use of high doses of propofol and fentanyl and excessive depth of anesthesia, as shown in table 3. Several other risk factors have also been associated with the incidence of POCD. Hypotension during surgery is the leading risk factor for POCD. Hypotension is the simplest and most common cause of cerebral hypoperfusion and decreased cerebral flow. The latter has been considered a significant risk factor for POCD in most early studies. Pain is also considered a risk factor for POCD as the areas of the brain involved in pain perception and cognitive control overlap. ${ }^{9}$

Intraoperative awareness was not found in this study. Other side effects in PONV and moderate to severe pain during recovery in the PACU room were similar between the two groups, as shown in table 3. A higher number of samples are needed to evaluate if there are different intraoperative awareness, PONV, and pain in PACU between the two groups.

\section{Conclusion}

Using the CONOX monitor, the anesthesiologist can predict the depth of anesthesia of the patients and adjust the anesthesia or analgesia drug without exceeding the dose needed and increasing the side effect. This pilot study is a preliminary study to evaluate the benefit of using an EEG-based monitor. More samples are required to prove the adequacy of anesthesia depth level to avoid inadequate anesthesia and analgesia.

\section{Acknowledgment}

The authors report no conflict of interest. It is not being considered for publication, nor has it been published in whole or in part elsewhere. All authors have contributed intellectually to the work, participated in the work to the extent that he can defend the contents and have read the manuscript before its submission for publication. It has been submitted with the full knowledge and approval of the institution.

\section{References}

1. Bruhn J, Myles PS, Sneyd R, et al. Depth of anaesthesia monitoring: What's available, what's validated and what's next?'. British Journal of Anaesthesia. 2006;97(1):85-94. DOI: 10.1093/bja/ael120

2. Aryafar M, Bozorgmehr R, Alizadeh R, et al. A cross-sectional study on monitoring depth of anesthesia using brain function index among elective laparotomy patients. International Journal of Surgery Open. 2020;27:98102. DOI: $10.1016 /$ j.ijso.2020.11.004

3. Jildenstål PK, Hallen JL, Rawal N, et al. Does depth of anesthesia influence postoperative cognitive dysfunction or inflammatory response following major ENT surgery?. Journal of Anesthesia and Clinical Research. 2012: 3(6). DOI: $10.4172 / 2155-6148.1000220$

4. Upton HD, Ludbrook GL, Wing A, et al. Intraoperative "analgesia nociception index"-guided fentanyl administration during sevoflurane anesthesia in lumbar discectomy and laminectomy: A randomized clinical trial'. Anesthesia and Analgesia. 2017;125(1):81-90. DOI: 10.1213/ANE.0000000000001984

5. Jensen EW, Valencia JF, Lopez A, et al. Monitoring hypnotic effect and nociception with two EEG-derived indices, qCON and qNOX, during general anaesthesia. Acta Anaesthesiologica Scandinavica. 2014;58(8):933-941. DOI: 10.1111/aas.12359

6. Zanner R, Schneider G, Meyer A, et al. Time delay of the qCON monitor and its performance during state transitions. Journal of Clinical Monitoring and Computing. 2020;9(2):123-42. DOI: 10.1007/s10877-020-00480-4

7. Wehrmann T, Grotkamp J, Stergiou N, et al. Electroencephalogram monitoring facilitates sedation with propofol for routine ERCP: A randomized, controlled trial. Gastrointestinal Endoscopy. 2002;56(6):817824. DOI: $10.1067 /$ mge.2002.129603

8. Yli-Hankala Al, Vakkuri A, Annila $\mathrm{P}$, et al. EEG bispectral index monitoring in sevoflurane or propofol anaesthesia: Analysis of direct costs and immediate recovery. Acta Anaesthesiologica Scandinavica. 1999;43(5):545-549. DOI: 10.1034/j.1399-6576.1999.430510.x

9. Rundshagen I. Postoperative cognitive dysfunction. Deutsches Arzteblatt International. 2014;111(8):119-125. DOI: 10.3238/arztebl.2014.0119 